\title{
EDUCAÇÃO, INCLUSÃO SOCIODIGITAL E O SISTEMA BRASILEIRO DE TELEVISÃO DIGITAL
}

\author{
EDUCATION, SOCIO-DIGITAL INCLUSION \\ AND THE BRAZILIAN DIGITAL TV SYSTEM \\ ÉDUCATION, INCLUSION SOCIO-DIGITALE ET LE \\ SYSTEME BRESILIEN DE TELEVISION DIGITALE \\ EDUCACIÓN, INCLUSIÓN SOCIODIGITAL Y EL \\ SISTEMA BRASILEÑO DE TELE DIGITAL
}

\author{
Nelson De Luca Pretto* \\ Simone de Lucena Ferreira **
}

\begin{abstract}
RESUMO
Um dos maiores desafios do Brasil é disponibilizar ao maior número de pessoas o acesso às tecnologias de informação e comunicação. $O$ artigo apresenta algumas reflexóes sobre a implantação do Sistema Brasileiro de Televisão Digital Terrestre (SBTVD-T), lançado pelo Decreto 5.820/2006, por meio do qual o governo brasileiro fez uma opção técnica impregnada por pressóes políticas. A implantação da TV digital no País foi seguida por inúmeras transformaçôes ao longo do seu percurso, tendo envolvido pesquisadores de diversas áreas, tanto técnicas como sociais, com o objetivo de desenvolver um sistema que atendesse as necessidades da sociedade brasileira, incluindo a conexão à internet. Na perspectiva de inclusão sociodigital que propomos, a televisão digital pode se constituir em um importante elemento da transformação da educação com vistas à formação de cidadãos, e não de meros consumidores, seja de produtos, seja de informaçôes.
\end{abstract}

Palavras-chave: Educação. TV digital. Interatividade. Currículo. Inclusão digital.

* Doutor em Comunicação pela Universidade de São Paulo (USP, 1994). Professor e Diretor da Faculdade de Educação da Universidade Federal da Bahia (UFBA, 2000-2008). Autor, entre outros, de SMOG Crônicas de Viagens (Arcádia, 2004), Uma escola sem/com Futuro (Papirus, 1996) e organizador de Tecnologia e Novas Educações (Edufba, 2005). Criador do projeto Tabuleiro Digital [www.tabuleirodigital.org]. Pesquisador do CNPq (nelson@pretto.info, www.pretto.info).

** Doutoranda do Programa de Pós-Graduação em Educação da UFBA. Mestre em Educação pela Universidade Federal de Santa Catarina (UFSC, 2004). Professora do Núcleo de Tecnologia Educacional (NTE2) da Secretaria da Educação do Estado da Bahia. Professora Substituta de Didática da Faculdade de Educação da UFBA (slucen@ufba.br). 


\section{A EDUCAÇÃO NO SINGULAR}

Nos últimos 50 anos, a educação, seja ela presencial, seja a distância, vem passando por grandes transformações, principalmente com o desenvolvimento e a utilização das Tecnologias de Informação e Comunicação (TIC). Atualmente, novos espaços e ambientes telemáticos que utilizam diversas mídias têm sido desenvolvidos para a educação. No entanto, ao mesmo tempo, é possível encontrar, nesses novos ambientes, modelos de educação pautados num paradigma linear de comunicação entre um emissor único (professor) e os receptores (alunos). Criam-se vídeos, páginas individuais e portais educativos onde os alunos assistem ou baixam arquivos e textos que são, simplesmente, postados pelo professor. Em alguns casos é permitido ao aluno participar apenas disponibilizando as suas tarefas, ou seja, enviando as respostas daquilo que lhe foi solicitado pelo professor. Será essa a única forma de a educação se relacionar com as tecnologias sem superarmos as concepções instituídas da educação? Certamente que não. Acreditamos ser viável buscar outras possibilidades para a educação que estejam fundamentadas em estruturas não-lineares, como a das redes de informação e comunicação, com o objetivo de possibilitar que o aluno seja sujeito construtor do seu processo de aprendizagem, que poderá, assim, ser feito de forma coletiva e colaborativa.

Vivenciamos hoje diferentes práticas sociais e interativas nos ambientes virtuais existentes na internet. Nesses espaços, jovens e adultos, alunos e professores poderiam interagir de forma horizontal, construindo saberes significativos. $\mathrm{O}$ conhecimento passa a se constituir de forma não hierarquizada, numa perspectiva de rede na qual diferentes autores vão produzindo coletivamente. Buscamos com isso superar as "pedagogias da assimilação" (PRETTO, 2005), que, com algumas variações metodológicas, vão buscando trazer para os estudantes o conhecimento instituído num processo de muito pouca troca. Nessa perspectiva, o que temos visto é a escola ser confundida com o sistema de produção industrial, que é incompatível com a idéia de espaços de aprendizagem e de ensinamento para a formação da cidadania.

Numa outra perspectiva, o que se deseja é a implantação de processos em que, respeitadas as condições locais, não se busque a identificação de um centro único, estável, fixo, e sim uma centralidade instável. Tanto professores como alunos, assim como um outro integrante de todo esse processo, que pode ser um familiar, um membro da comunidade ou um convidado externo, passam a ser o centro, um centro momentâneo. Estabelecem-se, com isso, processos horizontais sem a hierarquia e a verticalidade que são próprias da cultura pedagógica e que, nas palavras de Luiz Felippe Serpa, "são incompatíveis com a lógica e a pedagogia das tecnologias contemporâneas, já que essas funcionam em rede" (SERPA, 2004, p. 173). ${ }^{.}$Outras possibilidades podem ser geradas a partir do desejo de pensarmos a educação numa perspectiva plural, demandando, portanto, pensarmos em outras educações, onde, como já nos referimos, os centros são móveis, não estando fixos o tempo todo no professor. Desta forma, acreditamos ser possível intensificar a interação 
entre todos os envolvidos no processo educativo, tornando-se todos, assim, autores e co-autores de culturas e conhecimentos. Neste sentido, muda a própria forma de se constituir a escola e os papéis dos professores e alunos. Como afirma, novamente, Serpa (2004, p. 173):

...todo sujeito, para vivenciar o processo pedagógico, tem que participar na rede, sendo impraticável um mero assistir. Sincronicidade de atenção a várias coisas na aprendizagem - a profundidade não se dá através de um conceito de verticalidade, mas sim em um conceito espaço-temporal. Na verdade, é o espaço sincrônico e o tempo espacializado. Ambigüidade entre a oralidade e a escrita - as dinâmicas comunicacionais na rede, mesmo com o uso da escrita, expressam-se com uma alta dimensão de oralidade, incluindo-se nessa expressividade as imagens. Processos coletivos necessários - sendo uma dinâmica de rede e necessitando da participação de todos, a produção é necessariamente coletiva. Cooperação como traço fundamental - para o sistema de rede funcionar, os participantes necessariamente têm que cooperar.

É notório que a educação instituída, pautada no paradigma da transmissão (emissãorecepção), não cabe mais na sociedade contemporânea, na qual os sujeitos estão interagindo nos espaços socioculturais e na cibercultura. É curioso como Pierre Babin, em 1989, colocava que a juventude - na época sem nenhum contato com isso que hoje denominamos de cibercultura - já estava "em outra", referindo-se à geração que interagia com o audiovisual, já procurando intensificar o nível de intervenção e de interatividade, buscando afastar a idéia de meros espectadores de produçôes produzidas por outrem.

Identificamos, assim como outros autores, um esgotamento da educação instituída, que tem a ver, como propõe Fernando Ramos, da Universidade de Aveiro, com o "desenvolvimento e penetração das tecnologias de comunicação, muito em especial das alterações desencadeadas e alimentadas pela internet, quer nos meios quer nas mentalidades, ao longo da última década" (RAMOS, 2002, p. 138). Buscar formas interativas para novas educações pode ser uma importante contribuição para a construção de espaços educacionais abertos, capazes de formar sujeitos transformadores, algo imprescindível na sociedade contemporânea, cada vez mais permeada pelas TIC, que, potencialmente, é bom que se insista sempre nesse aspecto, possibilitariam o aumento da participação e da horizontalidade nas relações e, com isso, a possibilidade de formação de sujeitos transformadores, atuantes, críticos e autônomos. Para Paulo Freire, a educação se fundamenta no mundo da comunicação, onde o homem está em relação com os outros homens e com a natureza. Freire foi um dos primeiros educadores brasileiros a perceber a estreita relação entre educação e comunicação, pois, para ele, não há educação sem diálogo e sem comunicação. Ao contrário, a educação feita de maneira unidirecional, na qual o professor "deposita" os conteúdos e as informaçôes no aluno para que este assimile de forma passiva, foi por ele denominada de "educação bancária" (FREIRE, 1979), constituindo-se num marco na educação a sua critica a esse processo.

Há muito tempo percebemos entre educadores o desejo de promover uma forte articulação da educação com os meios de comunicação e informação. Essa é uma história 
que possui relativamente longo percurso, com vários pesquisadores brasileiros já tendo se debruçado sobre o tema. No campo da informática, um número temático do Em Aberto, ${ }^{2}$ publicação do Inep de 1993, resgata essa história através de autores como Maria Cândida Moraes, Jorge Armando Valente, Afira Ripper, Carlos Seabra entre outros (Revista Em Aberto, 1993). Na relação da educação com a comunicação, podemos destacar os trabalhos da UCBC (União Cristã Brasileira de Comunicação), com os trabalhos de Ismar de Oliveira Soares (1992 e 1996), José Manuel Moran (2000) e Maria Luiza Belloni (1991 e 1998), para ficar em apenas alguns nomes. Nessa trajetória, encontramos, para não ir muito aquém da década de 90 do século passado, projetos como o Educom (1983), o Cied (1986), a TV Escola (1996) e o Proinfo (1997), que foram criados com o intuito de inserir as tecnologias na educação como forma de melhorar o processo de ensino e de aprendizagem.

Num primeiro momento, esse movimento de aproximação se deu como uma mera extensão ou uma simples evolução das tecnologias disponíveis anteriormente, continuando a ser pensadas apenas como recursos didáticos que seriam capazes de motivar as aulas que tradicionalmente eram apresentadas, ou sem estes equipamentos, ou com equipamentos superados. Esperava-se que os mesmos conteúdos trabalhados com os livros didáticos agora pudessem ser abordados utilizando-se os "novos" recursos tecnológicos, muitas vezes repetindo até mesmo a estrutura ali proposta, sem reconhecer as diferenças dos suportes envolvidos, suas naturezas e sintaxes. Vivenciamos isso com as máquinas de ensinar da década de 70 do século passado, centradas em teorias behavioristas, utilizando as instruçôes, os programas impressos, a televisão e os vídeos educativos, que, inclusive, produziam tele-aulas, com professores simplesmente falando em frente a um quadro negro (ou verde!), ou quando, hoje, entramos em uma sala de informática e nos deparamos com um professor e cerca de 20 ou 30 alunos, todos com a mesma tela da internet à sua frente, copiando no caderno as informações do site. Essa perspectiva, que denominamos de instrumental (PRETTO, 1996), não dá conta dos desafios contemporâneos, ao mesmo tempo em que não possibilita utilizar os novos recursos como elementos estruturantes de novas formas de ser, pensar e agir, coerentes com a contemporaneidade. Nós, assim como Canclini (2001), pensamos na formação de cidadãos plenos, e não de meros consumidores de produtos globalizados.

Em Mestres de amanhã, Anísio Teixeira (1963) alertava para a necessidade de os professores se apropriarem das potencialidades tecnológicas pois estas iriam transformar a sua prática pedagógica:

os novos recursos tecnológicos e os meios audiovisuais irão transformar o mestre no estimulador e assessor do estudante, cuja atividade de aprendizagem deve guiar, orientando-o em meio às dificuldades da aquisição das estruturas e modos de pensar fundamentais da cultura contemporânea de base científica em seus aspectos físicos e humanos. Mais do que o conteúdo do conhecimento em permanente expansão, cabe-lhe, com efeito, ensinar ao jovem aprendiz 
a aprender os métodos de pensar das ciências físico-matemáticas, biológicas e sociais, a fim de habilitá-lo a fazer de toda a sua vida uma vida de instrução e estudos. ${ }^{3}$

Os desafios colocados aos mestres por Anísio Teixeira em 1963 ainda continuam sendo os mesmos desafios existentes neste inicio de século XXI, sendo que agora estamos pautados pelas comunicações globalizadas, através de redes telemáticas planetárias. Rede essa que no Brasil, assim como em diversos outros países, só está disponível a cerca de $13,7 \%$ da população. ${ }^{4}$ Não resta a menor dúvida de que necessitamos de políticas públicas que busquem dar conta desse chamado fosso digital, mas também não temos dúvida de que isso não acontecerá nem a curto nem a médio prazo se concentramos esforços somente em soluções individualizadas. Nesse sentido, as escolas públicas passam a ter importante papel na democratização do acesso a essas tecnologias como forma de aumentar o número de pessoas conectadas à rede, principalmente aquelas pertencentes às classes sociais menos favorecidas economicamente. Podemos observar que esse movimento já deu frutos, pois em $2000^{5}$ tínhamos $80 \%$ das classes A e B com acesso a internet, contra $16 \%$ da classe $\mathrm{C}$ e $4 \%$ das classes D e E. Ao tempo que, com dados relativos a março de $2006,{ }^{6}$ observamos um crescimento significativo no número de internautas nas classes de menor poder aquisitivo. Esses dados indicam que o acesso à internet para a classe C é de $25 \%$, e das classes $\mathrm{D}$ e E é de $11 \%$. Isso, sem dúvida, é devido às recentes políticas de apoio à implantação de telecentros/infocentros comunitários e de políticas para venda de computadores populares em toda a América Latina na última década (LAPNANE, 2006). Entretanto, associado a isso, é importante que as escolas estejam conectadas, possibilitando, também, que a comunidade local possa utilizar esse espaço como ponto de acesso. O que até agora foi feito não é pouco, é bem verdade, mas é ainda insuficiente se consideramos o tamanho do desafio para um país como o Brasil. Outras frentes necessitam ser abertas, e a convergência tecnológica que o mundo experimenta em nossos dias pode se constituir num importante salto na busca da diminuição das desigualdades. A televisão digital, talvez, seja a maior de todas essas possibilidades de democratização se, de fato, pudermos implantá-la numa perspectiva de inclusão sociodigital, conforme, aliás, está preconizado nos objetivos estabelecidos no próprio Decreto 4.901/2003, que instituiu o Sistema Brasileiro de Televisão Digital (SBTVD).

\section{EDUCAÇÃO ETV DIGITAL}

A televisão analógica há algum tempo já foi relativamente inserida na escola, ${ }^{7}$ embora o seu uso nas práticas pedagógicas ainda seja limitado devido à falta de condições técnicas, de trabalho e de preparo do professor para utilizá-la de forma crítica, visando proporcionar ao aluno uma análise da realidade que o cerca. Em geral, quando a televisão e o vídeo são usados em sala de aula, são quase sempre para assistir programas educativos ou filmes que se enquadram nas chamadas "grades curriculares". Em atividades como 
essas, cabe ao aluno ser apenas o telespectador de conteúdos produzidos por outrem sem grandes possibilidades de fortalecimento de suas crenças e culturas.

$\mathrm{O}$ advento da TV digital permitirá a utilização de recursos que antes não eram possíveis com o sistema de transmissão analógico, já que poderá proporcionar, em teoria, a bidirecionalidade, ou seja, o uso de um canal de retorno que a tornaria interativa, sendo assim potencializadora de espaços não-lineares e coletivos de construção de conhecimentos e culturas. Ao pensar em novas educações para a televisão digital é imprescindível a interatividade, pois esta será uma das possibilidades de alunos e professores tornarem-se autores e co-autores de conhecimentos significativos. Novas linguagens e novas formas de sociabilidades serão construídas por meio de relaçōes horizontais em espaços dialógicos que priorizem a formação para o exercício da cidadania.

Ao falarmos de interatividade, é importante sinalizar a que concepção de interatividade estamos nos referindo. Marco Silva (2000) nos alerta para a polissemia do termo interatividade e para a sua banalização. Atualmente vende-se tudo como sendo interativo. Dizer que um produto é interativo significa dizer que o público terá alguma forma de participação (FERREIRA, 2004), e, neste sentido, anuncia-se "um show interativo, um restaurante interativo (do tipo self-service), uma peça teatral, um brinquedo (eletrônico ou não), um game, um CD, etc.” (SILVA, 2000 p. 88). Arlindo Machado (1997, p. 250) reforça essa concepção mercadológica: "o termo interatividade se presta hoje às utilizações mais estapafúrdias, abrangendo um campo semântico dos mais vastos, que compreende desde salas de cinema em que as cadeiras se movem até novelas de televisão em que os espectadores escolhem (por telefone) o final da história”.

Em 1979, Raymond Williams nos chamava a atenção para o fato de que as tecnologias vendidas àquela época como sendo "interativas", na verdade, eram de tecnologias "reativas", pois diante delas os sujeitos apenas realizavam escolhas entre alternativas disponibilizadas pelo produtor do conteúdo. Para ele, interatividade significava a intervenção total do sujeito no conteúdo, com resposta autônoma e criativa e a liberação total do pólo emissor e receptor. De forma semelhante, Bertold Brecht (1967) falava de interatividade como um processo de inserção democrática nos meios de comunicação, com participação direta dos cidadãos no sistema radiofônico alemão.

No campo educacional, superar essas perspectivas mercadológicas é fundamental para que possamos pensar na educação, no plural pleno que reivindicamos, como espaço privilegiado da interatividade, onde os sujeitos (alunos, professores e sociedade) possam se colocar de forma critica, criativa e autônoma, com seus valores, conhecimentos e produções. Para tanto, é preciso pensar que a educação que estamos querendo com a TV digital não pode ser reduzida a uma educação de massa - de uma massa sem rosto! - que apenas prepare novos consumidores para o mercado.

Neste sentido perguntamos: quais elementos do novo Sistema de Televisão Digital que ora se implanta no Brasil estão sendo pensados na busca de formar sujeitos produtores 
de cultura e conhecimento, e não apenas receptores de conteúdos e informações? As questôes que nos colocamos, enquanto cidadãos e educadores, buscam identificar quais as reais possibilidades com a TV digital para que ela possa contribuir, já que nesse campo estão acontecendo grandes investimentos, com a radical transformação e ampliação da educação no País. Para a educação, é imprescindível que a TV digital seja interativa, com possibilidades de total liberação do pólo emissor-receptor, possibilitando às escolas estarem imersas nesse potencial de criação e não, simplesmente, recebendo os mesmos conteúdos, com imagem e som em alta definição. Mas não só as escolas, já que a TV analógica está presente em 95,7\% dos domicílios brasileiros, ${ }^{8}$ sendo, portanto, um importante veículo de comunicação, com grandes possibilidades de formação. Para que tenhamos uma comunicação democrática, o sistema brasileiro precisará priorizar a TV digital aberta e igual para todos, não sendo admissível que se diferencie, através de mecanismos econômicos seletivos, as classes sociais, oferecendo para as famílias de alto poder aquisitivo todas as possibilidades e recursos da interatividade e da alta definição e, para as famílias pobres, a mesma televisão broadcasting, com distribuição centralizada de uma produção realizada apenas nos grandes centros, reservando a essa população somente a possibilidade de reagir comercialmente à programação.

\section{O SISTEMA BRASILEIRO DE TELEVISÃO DIGITAL TERRESTRE (SBTVD-T)}

Embora as discussões sobre TV digital (TVD) estejam mais em evidência nos dois últimos anos, os estudos sobre a sua implantação no Brasil não são recentes. No final da década de 1990 foram iniciados testes de campo entre os três maiores sistemas de TVD em funcionamento no mundo (o norte-americano ATSC, o europeu DVB e o japonês ISDB). Esses testes foram realizados pela Abert (Associação Brasileira de Emissoras de Rádio e TV), pela SET (Sociedade de Engenharia de Televisão e Telecomunicações) e pela Universidade Mackenzie. Ao longo desse tempo, foram feitos estudos técnicos e mercadológicos pela Fundação $\mathrm{CPqD}^{9}$ (Centro de Pesquisa e Desenvolvimento em Telecomunicaçôes) a partir de uma demanda da Anatel (Agência Nacional de Telecomunicaçôes), que coordenava nesse período as pesquisas referentes à TVD. A pesquisa feita pelo $\mathrm{CPqD}$ tinha como objetivo identificar os principais fatores que levaram à adoção da TV digital em diversos países, bem como conhecer o plano de implantação dessa tecnologia nos países pioneiros. Foram analisados os casos da Alemanha, Austrália, Canadá, Cingapura, Espanha, Estados Unidos, França, Itália, Japão, Portugal, Reino Unido e Suécia. Os estudos do $\mathrm{CPqD}$ indicaram que os modelos adotados em cada um desses países foram adaptações dos tradicionais modelos, de forma a atender suas necessidades regionais, socioculturais e mercadológicas. Segundo o CpqD, apenas Austrália, Canadá, Estados Unidos e Japão fizeram a opção pela imagem em alta definição (HDTV), uma vez que, nesses países, a população já é bem atendida por outras formas de transmissão de sinais de TV (satélite e/ou cabo) e possuem um bom nível de inclusão 
digital, não necessitando, desta forma, de uma televisão digital interativa que possa também dar acesso à internet.

Em 2003, com a mudança no governo brasileiro, foi iniciada uma nova etapa, com a reabertura dos debates sobre a implantação da televisão digital no Brasil. Desejava-se criar um sistema de TV digital nacional que evitasse a dependência tecnológica e o pagamento de royalties e, para tanto, seria necessário investir no desenvolvimento de pesquisas na indústria nacional. Mudou-se o foco da política pública até então vigente e, no lugar de se buscar qual sistema seria o melhor, procurou-se responder à questão: o que queremos com a televisão digital no País? Dessa forma, foi instituído o Sistema Brasileiro de Televisão Digital (SBTVD), por meio do Decreto no 4.901 de 26/11/2003, com, entre outros, os seguintes objetivos: promover a inclusão social, a diversidade cultural e a democratização da informaçãa, bem como propiciar a criação de rede universal de educação à (sic!') distância.

Para a operacionalização do projeto do SBTVD foram estimuladas parcerias entre 79 instituições, em 22 consórcios que incluíram empresas, universidades e centros de pesquisa brasileiros, atendendo às Chamadas Públicas realizadas pelo Ministério das Comunicações e Ministério da Ciência e Tecnologia (MCT) através da Finep (Financiadora de Estudos e Projetos, vinculada ao MCT) e com recursos do Funtel (Fundo Nacional de Desenvolvimento de Tecnologia em Telecomunicações). As instituições selecionadas deveriam estar aptas a desenvolver projetos nas áreas de difusão e acesso; terminal de acesso e serviços; e aplicações e conteúdo, dentro dos seguintes temas:

a) transmissão e recepção, codificação de canal e modulação;

b) camada de transporte;

c) canal de interatividade;

d) codificação de sinais fonte;

e) middleware;

f) serviços, aplicações e conteúdo.

As pesquisas realizadas para a elaboração do SBTVD acabaram despertando interesse de outros países da América Latina, como Argentina, Venezuela e Peru, uma vez que os estudos consideravam as realidades socioeconômicas locais associadas aos aspectos técnicos. Nesta perspectiva iniciava-se para o Brasil uma grande possibilidade de se constituir numa referência para a América Latina.

Ao longo desse período de cerca de dois anos, muita polêmica acompanhou os estudos e a discussão sobre a televisão digital no Brasil. De um lado, as emissoras de televisão pressionavam para uma imediata definição/escolha do sistema a ser adotado para, rapidamente, poderem estar adaptadas e usufruírem dos recursos técnicos e mercadológicos da televisão digital. De outro, setores organizados da sociedade civil e pesquisadores de 
universidades buscavam uma solução mais adequada para aquilo que entendíamos estar definido no Decreto 4.901/2003: promover a inclusão social, a diversidade cultural e a democratização da informação, bem como propiciar a criação de rede universal de educação a distância. Em 2005, uma mudança na equipe ministerial, a partir do jogo político de repartição de ministérios no Governo Lula, que buscava garantir a governabilidade do País, possibilitou que o PMDB colocasse o senador Hélio Costa, ex-apresentador da Rede Globo de Televisão e também proprietário de emissoras de rádios comerciais, como o novo titular da pasta das comunicações, justamente a responsável pela condução do SBTVD. A partir daí, um forte movimento dentro e fora do governo traz para o campo de discussão sobre a televisão digital novos elementos, intensificando-se o embate entre a sociedade civil, os grupos de mídia e telecomunicações e o governo federal. ${ }^{10}$ Aqui não vamos aprofundar esse importante aspecto político da temática; no entanto, registramos apenas que o que aconteceu após essa mudança de rumo no governo federal foi um relativo esvaziamento dos consórcios, uma pressão política muito forte de diversos parlamentares que buscavam garantir uma televisão digital nacional e democrática. No entanto, apesar desses esforços, em 29 de junho de 2006, através do Decreto 5.820/ 2006, o governo federal implantou o SBTVD-T (acrescentando o T de Terrestre na nomenclatura), adotando o padrão japonês, assim definindo:

I - SBTVD-T - Sistema Brasileiro de Televisão Digital Terrestre - o conjunto de padrões tecnológicos a serem adotados para transmissão e recepção de sinais digitais terrestres de radiodifusão de sons e imagens.

II - ISDB-T - Integrated Services Digital Broadcasting Terrestrial - serviço de radiodifusão digital terrestre, integrado por padrōes tecnológicos internacionais definidos na União Internacional de Telecomunicações - UIT.

Percebe-se que a opção feita nesse decreto, ao adotar o padrão japonês como base tecnológica para a implantação do SBTVD-T, não considerou os objetivos propostos pelo Decreto 4.901/2003 e muito menos as pesquisas desenvolvidas pelas instituições científicas que fizeram parte dos 22 consórcios financiados com investimentos públicos. Mais do que isso, ao longo do primeiro semestre de 2006, a sociedade brasileira acompanhou esse debate em que, de um lado, estava parte do governo, inclusive com discussão pública entre ministros, as emissoras de televisão defendendo a imediata escolha de um sistema, com a defesa clara do padrão japonês, e, de outro, grupos organizados ${ }^{11} \mathrm{da}$ sociedade civil, defendendo mais estudos e menos pressa nessa definição, justamente pelo momento eleitoral que vivia o País. $\mathrm{O}$ argumento usado para a não-necessidade de uma imediata decisão, baseava-se no fato de que, em praticamente todo o mundo, essa ainda é uma discussão muito nova, não havendo grandes prejuízos se a mesma fosse ampliada, aprofundando-se as pesquisas e afastando as decisões políticas de momentos conturbados como os pré-eleitorais. 
O jornal português Diário de Noticias (DN. 25/08/2006, p. 2, Caderno Economia) apresentou um panorama da situação atual de implantação da TV Digital na Europa. Segundo o jornal, o país que mais avançou nesse processo foi a Finlândia, que iniciou o processo em 2001, tendo hoje uma penetração em 25\% dos lares finlandeses, com previsão para 2007 do switch off analógico, ${ }^{12}$ seguido do Reino Unido, que começou implantar o sistema em 1998, mas que também só está presente em 26\% dos lares, tendo o switch off analógico previsto somente para o ano 2012. Os países europeus mais atrasados são Malta e Luxemburgo, que somente agora estão dando início ao processo de implantação da televisão digital. É interessante observar também que, de acordo com o referido jornal, dos 19 países europeus analisados (na verdade a Comunidade Européia é atualmente composta por 25 países membros), 11 deles iniciaram esse processo a partir de 2005. É esse o principal argumento que considera ser esse um processo relativamente novo, o que justifica, no caso brasileiro, a crítica que com freqüência se faz à pressa do atual governo brasileiro, em um ano de eleição presidencial, em definir-se rapidamente por um dos sistemas em estudo. Além disso, o que se viu nesses últimos movimentos foi uma não-articulação com os demais países da América Latina, que, de certa forma, aguardavam as movimentaçōes brasileiras, sem tomar posiçōes definitivas, com grandes possibilidades de seguirem o padrão brasileiro se as articulações fossem feitas.

Tanto na Europa e América Latina, como no Brasil, as questões são, basicamente, as mesmas e dizem respeito a:

i. custo para o consumidor final;

ii. modelo de negócios, principalmente sobre a possibilidade de distribuição de canais abertos e não pagos para toda a população;

iii. sistema adotado e as possibilidades que ele oferece para uma maior interatividade.

Para a educação, aqui se iniciam as reais possibilidades do sistema, uma vez que, no caso brasileiro, se consideramos que $95,7 \%$ dos lares possuem aparelhos de televisão, esse pode ser um enorme potencial de formação para a cidadania. O que temos defendido é que a TV digital possa proporcionar novas formas interativas entre os indivíduos, inserindo assim possibilidades de novas educações, com forte privilegiamento nas dimensões culturais de todas as regiōes do País.

\section{NOVAS EDUCAÇÕES}

Discutir novas educações, particularmente com a presença da TV digital, significa pensarmos em diversos e polêmicos aspectos da questão. O primeiro deles é que essa discussão sobre TV digital no Brasil pode passar meio que despercebida por grande parte da sociedade - incluindo aí, lamentavelmente, muitos educadores! -, porque, como nos alerta Regina Mota, a dificuldade de agendamento desse debate na sociedade é devido ao fato de a "mídia eletrônica estar simultaneamente tão próxima dos cidadãos quanto está 
distante de possíveis deliberações destes a respeito dela”. Para ela, portanto, "é razoável pensar que uma luta pelo acesso à mídia eletrônica não faz parte do imaginário desses cidadãos e seria muito difícil esperar uma demanda organizada ou a lista de prioridades que definiriam uma política para o setor" (MOTA, 2005 p. 226).

Neste sentido, para pensarmos numa televisão digital democrática e interativa precisamos inserir este debate em diversos espaços públicos, e de forma mais intensa nas escolas, faculdades, universidades, em especial nos centros formadores de professores. Contudo, não basta apenas inserir essa discussão para os educadores sem articulá-la com uma profunda reflexão sobre o currículo que ainda é fragmentado e muitas vezes confundido com a idéia de "grade" de disciplinas. Podemos entendê-lo como um espaço (real e virtual) de produção de culturas e conhecimentos, de diálogo com outros autores e culturas. Como afirmam Antonio Flávio Moreira e Tomáz Tadeu Silva, "o currículo é, assim, um terreno de produção e de política cultural, no qual os materiais existentes funcionam como matéria-prima de criação e, sobretudo, de contestação e transgressão" (MOREIRA; SILVA, 1995, p. 28).

Nosso desafio hoje é pensar em uma outra forma de currículo, que insira as tecnologias de informação e comunicação como elemento estruturante e articulador das produções de conhecimentos e culturas. Nesta perspectiva, Edméa Oliveira Santos (2004), umas das pesquisadoras do nosso grupo de pesquisa na Faced/UFBA, ${ }^{13}$ apresenta o currículo como sendo:

uma rede de relaçôes complexa e interativa que articula os "nós" da prática dos espaços de aprendizagem com os "nós" dos arranjos sociais, econômicos, culturais e políticos. Em outras palavras, temos uma implicação mútua entre escola e sociedade. Por estarmos envolvidos numa sociedade cada vez mais estruturada pelas tecnologias de comunicação e de informação, é fundamental percebermos como o paradigma digital vem também influenciando as práticas curriculares na construção de novas formas de trabalhar e aprender no mundo contemporâneo (SANTOS, 2004, p. 419).

Certamente, para pensarmos hoje em novas educações é imprescindível o uso das TIC. Contudo, vale ressaltar que essas tecnologias não estão disponíveis a todos e nem todos os espaços educacionais estão conectados à rede mundial de computadores. Sem dúvida, políticas públicas que favoreçam o acesso são imprescindíveis e podem contribuir para a diminuição do fosso digital, a que já nos referimos anteriormente. Mas não bastam as políticas nos campos das telecomunicaçôes e da infra-estrutura. Torna-se urgente pensar, simultaneamente, e aí reside exatamente o perigo e uma das maiores dificuldades, ${ }^{14}$ em políticas públicas que se articulem horizontalmente e envolvam inúmeras outras áreas, entre as quais destacamos, para o nosso caso, a educação, a cultura e a ciência e tecnologia.

Por fim, acreditamos ser fundamental resgatar o que já foi dito, e por isso também defendemos que todos os usuários, que são cidadãos plenos, tenham acesso aos serviços 
oferecidos pelo Sistema Brasileiro de TV digital, assim como a todos os demais serviços de telecomunicações, com padróes de qualidade e regularidade, em qualquer ponto do território nacional, não podendo ser discriminados quanto às condições de acesso e fruição do que lhes está sendo oferecido. Propositalmente não dissemos antes e nem aspamos a frase anterior, porque ela não é fruto de um possível devaneio intelectual nosso, mas sim, e nada mais nada menos, o artigo $3^{\circ}$ do Livro I (Dos princípios Fundamentais), da Lei Geral de Telecomunicações de 16 de julho de 1997 (BRASIL, 1997).

Dito isso, resta-nos pensar nas possibilidades legais, técnicas e políticas que nos permitam uma transformação radical no cenário de miséria do mundo contemporâneo e, para tal, acreditamos nas inúmeras possibilidades da televisão digital no Brasil, se não a deixarmos ser apropriada, como tudo, pelos poderosos de sempre.

\section{Notas}

1. Os textos de Felippe Serpa estão disponíveis em http://www.faced.ufba.br/rascunho_digital. Em 2004 esses textos foram revisados e publicados no livro: Rascunho digital: diálogos com Felippe Serpa, publicado pela Edufba.

2. MORAES, M. C. Informática educativa no Brasil: um pouco de história; Hiper, A. O ambiente Logo como mediador instrumental; Seabra, C. O computador na criação de ambientes interativos de aprendizagem; Valente, J. A. Diferentes usos do computados na educação; Semtec/MEC Programa Nacional de Informática Educativa - Proninfe.

3. TEIXEIRA, Anísio. Mestres de amanhã. Disponível na Biblioteca Virtual Anísio Teixeira http:/www.prossiga.br/anisioteixeira/eng/artigos/mestres.html. Texto publicado na Revista Brasileira de Estudos Pedagógicos, Rio de Janeiro, v. 40, n. 92, p. 10-19, out./dez. 1963.

4. Dados da Pesquisa Nacional por Amostra de Domicílios (PNAD) do Instituto Brasileiro de Geografia e Estatística (IBGE) 2005. Acesso em: 28 ago. 2006.

5. Fonte: Pesquisa Internet POP - maio 2000. Ibope e Ratings. Acesso em: 28 ago. 2006.

6. Fonte: <http://www.abranet.org.br/doc/ApresUOLmaio_06FJ1.pdf\#search=\%22pesquisa\%20 internet\%20pop\%202006\%22>. Acesso em: 28 ago 2006.

7. Destaque para o pioneiro projeto TV Escola, da Fundação Roberto Marinho, do TV Escola do MEC e do Canal Futura, também da Fundação Roberto Marinho, ligada às Organizações Globo de Comunicação.

8. Fonte: Pesquisa realizada pelo Comitê Gestor da Internet no Brasil sobre o uso das tecnologias da informação e comunicação no Brasil em 2005. Disponível em: http://www.cgi.br/.

9. O relatório dessa pesquisa do CPqD pode ser acessado em <http:/www.anatel.gov.br/radiodifusao/ tv_digital/partei.pdf\#search=\%22\%22para $\% 20$ os $\% 2012 \% 20$ paises $\% 20$ previamente $\% 20$ defi nidos\%3A\%20alemanha\%22\%22>. Acesso em: 20 jul. 2006.

10. Destacamos aqui o trabalho feito pelo Fórum Nacional pela Democratização da Comunicação (FNDC) [http://www.fndc.org.br] e do Centro de Mídia Independentes (CMI) [http://www.midiaindependente.org/], sítios que disponibilizam farto material sobre o tema. 
11. Dentre as várias organizaçōes, podemos citar: o Coletivo Intervozes (http://www.intervozes. org.br/), que produziu diversos artigos publicados na mídia impressa e on line; o FNDC Fórum Nacional pela Democratização da Comunicação (http://www.fndc.org.br/); a Frente Nacional por um Sistema Democrático de Rádio e TV Digital (http://www.frenteradiotv digitaldemocratica.org/) e o Mídia Independente (http://prod.midiaindependente.org), onde estão disponibilizados o Cordel da TV digital de autoria de Luciana Rabello (http:// prod.midiaindependente.org/pt/blue//2006/03/348361.shtml), bem como um vídeo sobre as pesquisas desenvolvidas pelos consórcio do SBTVD (http://www.midiaindependente.org/ pt/ blue/2006/06/356214.shtml).

12. Momento em que todos os sinais transmitidos de modo analógicos são interrompidos e não há mais possibilidade de recepção por aparelhos que não sejam os digitais ou adaptados para o novo sistema.

13. http://www.faced.ufba.br/gec.

14. Como já apontamos na pesquisa em andamento "Políticas Públicas Brasileiras em Educação, Tecnologia da Informação e Comunicação” apoiada pelo CNPq, coordenada por Nelson Pretto com a participação de Darlene Almada como bolsista de Iniciação Científica.

\section{Referências}

BABIN, Pierre; KOULOUMDJIAN, Marie-France. Os novos modos de compreender: a geração do audiovisual e do computador. São Paulo: Paulinas, 1989.

BELLONI, Maria Luiza. Educação para a mídia: missão urgente da escola. Revista Noésis, São Paulo, n. 17, p. 36-46, 1991.

. Estética da Violência. Revista Comunicação \& Educação, São Paulo: USP, n. 12, p. 43-48, 1998.

BRASIL. Decreto no 4.901/2003.Disponível em: <http://www.planalto.gov.br/ccivil_03/decreto/2003/D4901.htm>. Acesso em: 10 dez. 2005.

BRASIL. Decreto no 5.820/2006. Disponível em: <https://www.planalto.gov.br/ccivil_03/ _Ato2004-2006/2006/Decreto/D5820.htm>. Acesso em: 3 jul. 2006.

BRASIL. Lei Geral das Telecomunicaçôes (LGT) 1997. Disponível em: http://www.planalto. gov.br/ccivil_03/Leis/L9472.htm. Acesso em: 29 set. 2006.

BRECHT, Bertold. El compromiso en literatura y arte. Barcelona: Península, 1967.

CANCLINI, Nestor García. Consumidores e cidadãos: conflitos multiculturais da globalização. Rio de Janeiro: EdUFRJ, 1999.

FERREIRA, Simone de Lucena. Um estudo sobre a interatividade nos ambientes virtuais da internet e sua relação com a educação: o caso da AllTV. 2004. 164f. Dissertação (mestrado), Faculdade de Ciências da Educação. Universidade Federal de Santa Catarina, Florianópolis.

FREIRE, Paulo. Educação e mudança. Rio de Janeiro: Paz e Terra, 1979. . Extensão ou comunicação? 12. ed. Rio de Janeiro: Paz e Terra, 1977. . Pedagogia do oprimido. 14. ed. Rio de Janeiro: Paz e Terra, 1983. 
LAPLANE, Mariano Francisco. Casos de politicas públicas para aquisición de computadoras personales. Campinas: Unicamp e Cepal (Nações Unidas), 2006.

MACHADO, Arlindo. Pré-cinema \& pós-cinema. Campinas: Papirus, 1997.

MORAN, José Manuel et al. (Orgs.). Novas tecnologias e mediação pedagógica. Campinas: Papirus, 2000.

MOREIRA, Antonio Flávio; SILVA, Tomaz Tadeu da. Currículo, cultura e sociedade. São Paulo: Cortez, 1995.

MOTA, Regina. Os desafios da TV digital no Brasil. In: BARBOSA FILHO, André et al. (Orgs.). Midias digitais: convergência tecnológica e inclusão social. São Paulo: Paulinas, 2005, p. 199-224.

PRETTO, Nelson De Luca. Tecnologia e novas educaçôes. Salvador: EdUFBA, 2005.

. Uma escola sem/com futuro: educação e multimídia. Campinas: Papirus, 1996.

RAMOS, Fernando M. S. As tecnologias da comunicação no suporte aos sistemas eLearning. In: JAMBEIRO, Othon; RAMOS, Fernando (Org.). Internet e educação a distância. Salvador: EdUFBA, 2002.

REVISTA EM ABERTO, Brasília: Inep, v. 12, n. 57, jan./mar. 1993.

SANTOS, Edméa Oliveira dos. Idéia sobre currículo, caminhos e descaminhos de um labirinto. Educação e Contemporaneidade. Salvador: Faeeba, v. 13, n. 22, p. 417-430, jul./dez. 2004.

SERPA, Felippe. Rascunho digital: diálogos com Felippe Serpa. Salvador: EdUFBA, 2004.

SILVA, Marco. Sala de aula interativa. Rio de Janeiro: Quartet, 2000.

SOARES, Ismar de Oliveira (Org.). O jovem e a comunicação. São Paulo: Loyola, 1992. v. 1. . Sociedade da informação ou da comunicação?. São Paulo: Cidade Nova, 1996. v. 1.

TEIXEIRA, Anísio. Mestres de amanhã. Disponível na Biblioteca Virtual Anísio Teixeira http://www.prossiga.br/anisioteixeira/eng/artigos/mestres.html . Este texto foi publicado na Revista Brasileira de Estudos Pedagógicos, Rio de Janeiro, v. 40, n. 92, p. 10-19, out./dez. 1963. Acesso em: 28 ago. 2006.

WILLIAMS, Raymond. Television: techonology and cultural form. London: Routledge, 1990. 


\section{Education, socio-digital inclusion and the brazilian digital tv system}

\section{Abstract}

Among the greatest challenges currently facing the Brazilian government is the need to make information and communication technologies available to the largest portion of the population of the country. This paper presents some considerations on the implantation of the Brazilian System of Digital Television (SBTVD-T) launched by Federal Decree 5.820/2006, through which the Brazilian government made a technical option impregnated by political pressure. The implantation of the system has involved researchers from various areas, technological as well as social, aiming at developing a system which would satisfy the demands of Brazilian society, and including internet connection. From the perspective of digital inclusion proposed by us, digital television could become an important element in transforming the educational system in view of citizenship training instead of merely preparing to be mere consumers, whether of products or information.

Keywords: Education. Digital Television. Interactivity. Curriculum. Digital Inclusion.

\section{Éducation, inclusion socio-digitale et le système brésilien de TV digitale}

\section{Résumé}

Parmi les défis les plus grands auxquels le gouvernement brésilien doit faire face se trouve le besoin de rendre disponible les technologies de l'information et information au plus grand nombre de personnes dans le pays. Cette étude présente quelques considérations sur l'implantation du Système Brésilien de Télévision Digitale (SBTVD-T) lancé par le Décret 5.820/2006, au travers duquel le gouvernement brésilien a fait une option technique imprégnée de pression politique. L'implantation du système a impliqué des chercheurs de différents champs d'action, tant technologiques que sociaux, dans le but de développer un système qui satisfasse aux besoins de la société brésilienne, y compris la connexion à l'internet. À partir de la perspective d'inclusion digitale que nous proposons, la télévision digitale pourrait devenir un élément important pour transformer le système éducationnel en vue d'une formation pour la citoyenneté au lieu de penser à former seulement des consommateurs, que ce soit de produits ou d'information. Mots clefs : Éducation. Télévision Digitale. Interactivité. Curriculum. Inclusion Digitale.

\section{Educación, inclusión sociodigital y el sistema brasileño de tele digital Resumen}

Uno de los mayores desafios de Brasil es disponer al mayor número de personas el acceso a las tecnologías de información y comunicación. El artículo presenta algunas reflexiones sobre la implantación del sistema brasileño de televisión digital terrestre (SBTVD-T), lanzando por el decreto 5.820/2006, a través del cual el gobierno brasileño hizo una opción técnica impregnada por presiones políticas. La implantación de la tele digital en el país fue seguida por innumeras transformaciones al largo de su percurso, envolviendo pesquisadores de diversas, áreas, tanto técnicas como sociales, con el objectivo de desarrollar un sistema que atendiera las necesidades de la sociedad brasileña, incluyendo la conexión a la internet. En la perspectiva de inclusión digital que proponemos, la televisión digital puede constituirse en un importante elemento de la transformación de la educación para la formación de ciudadanía y no de meros consumidores, sean de productos o de informaciones.

Palabras-clave: Educación. Tele digital. Interactividad. Currículo. Inclusión digital.

Recebido em: 12.12.2006

Aceito em: 22.02.2007 
